\title{
The Effect of Classical Music on the Reading Comprehension of Iranian Students
}

\author{
Nasser Rashidi \\ Shiraz University, Shiraz, Iran \\ Email: Nrashidi@rose.shirazu.ac.ir \\ Farman Faham \\ Shiraz University, Iran
}

\begin{abstract}
The influence of music on language learning and performance has been the subject of study for many years. The purpose of the present study was to investigate the effect of classical music (Mozart Sonata) on the reading comprehension performance of two groups of Iranian students in an English institute in Iran. To this end, the study compared two groups of Iranian English students $(\mathrm{N}=60)$ over a period of three months: one was taught reading comprehension with a music background and the other with no music background whatsoever. The results of the study showed a significant difference between the performance of the group exposed to music and the performance of the other group not exposed to music. The group taught reading comprehension with a music background outperformed the other taught it with no music background.
\end{abstract}

Index Terms — reading comprehension, music, background music, classical music, Mozart sonata

\section{INTRODUCTION}

The use of music as a tool by language teachers to teach foreign languages has been the center of attention to researchers for many years. That is why in the literature we can see different, but mostly positive comments concerning the effectiveness of music in language learning and performance. It has been stated that music can contribute to acquiring the linguistic skills such as reading, writing, listening and speaking (Jalongo \& Bromley, 1984; Jolly, 1975; Martin, 1983; McCarthey, 1985). It is interesting to notice that not only teachers but also other scholars have benefited from the effect of music in their work "Throughout time, healers, philosophers, scientists, and teachers have recognized the role of music for therapeutic and developmental functions."(Bancroft, 1985 cited in Stansell, 2005).Stansell (2005) asserts that music has a positive effect on language accent, memory and grammar as well as mood, enjoyment, and motivation. Based on his assertion we can conclude that music can have some positive influences on both cognitive and affective traits of humans.

Regarding the affective filter hypothesis (Krashen, 1982), the degree of receiving linguistic input by the learner hinges on their inner feelings to a great extent. "Krashen theorizes that in unfavorable circumstances individuals develop negative attitudes that result in an affective filter, or mental block, that prevents them from using the input to internalize language." (Chastain, 1988, p.98). Krashen (1982) asserts that "The affective hypothesis implies that our pedagogical goals should not only include supplying comprehensible input, but also creating a situation that encourages a low filter" (p.32). Thus, if the learner is affected by negative feelings and attitude, their language internalization diminishes.

Now, the question is how the teacher can create a situation that encourages a low filter. Hallam and Price (1988 cited in Merrell, 2004) stated that particular combinations and frequencies of sounds have some positive effects on certain parts of the brain, brining calming effects to the students. They also reported that when music was playing in the classroom there were noticeable changes in body temperature, blood pressure, breathing rate, and pulse rate of the students and music helped the students to become calmer and more obliging. Merrell (2004) believes that music can reduce the level of anxiety and inhibition in learners, so he asserts that "Music can help to keep the levels of tension and stress to a minimum". Some researchers still talk more about the freeing influence of music, " Music therapists utilize both types of music (music to assuage and soothe, or music to arouse and energize) to relieve many kinds of psychological and physical stressors" (Stansell, 2005). When talking about the implications and reflections of his study, the effects of classical background music on fourth-grade silent reading comprehension, Drowns (2002) states that "During stressful moments, it (music) can help alleviate some of the pressure on both students and teachers, and serve as an outlet of expression or relaxation."

As such, if we believe that unfavorable circumstances can create negative feelings and attitudes which in turn can develop an affective filter in language learners (Chastain, 1988, p.98; Krashen, 1982. P. 32), then music by providing a suitable situation is capable of reducing the affective filter, and bringing about better language acquisition and performance.

Referring to Desuggestopedia (a method of language teaching), Larson-Freeman (2000) states that "The reason for 
our inefficiency, Lozanov asserts, is that we set up psychological barriers to learning" (p.73). When Larson-freeman (2000, p.79) talks about Desuggestopedia, she states that two planes are involved in communication: on one plane the linguistic message is encoded and on the other the linguistic message is influenced by other factors. On the former plane that is conscious the learner deals with the language and on the latter one that is subconscious the music tells that learning is nice and simple, and when subconciousness and consciousness join together, learning is improved. Also, we read through Richards and Rodgers (2001,) that:

The musical background helps to induce a relaxed attitude, which Lozanov refers to as concert pseudo-passiveness. This state is felt to be optimal for learning, in that anxieties and tension are relieved and power of concentration for new material is raised (p.102).

\section{A. Statement of the Problem}

Students are often stressed and anxious in language classes. "Learning a second language can be a stressful and difficult process." (Merrell 2004). Hence, it can develop a kind of mental block, or affective filter (Chastain, 1988, p.98; Krashen, 1982, p. 32) which in turn can prevent students from language internalization. In such a case, music can reduce their tension and stress (Drowns, 2002; Merrell, 2004; Stansell, 2005), and, in turn bring about better language learning including reading comprehension learning. Moreover, the positive effects that music can have on cognitive abilities including language learning in general and reading comprehension in particular (see, the related literature review) have often taken for granted, especially in Iranian English classes.

\section{B. Significance of the Study}

The significance of the present study can be discussed from two important points of view; firstly most studies regarding the effect of music on reading skills have just been based on exposing the participants to different musical conditions while they are taking a reading test. (see, Cooper, Cotton \& Goss 2008; Drowns ,2002; Liapis, Giddens \& Uhlenbrok 2008). However, the innovation with regard to this study was that the participants were both taught reading comprehension and tested on it in a music condition. To some extent the context of this study was similar to that of Desuggestopedia classes (a musical context), but with the emphasis on the reading comprehension skill. Secondly, a lot of studies have been conducted with regard to the effect of music on different cognitive abilities like language learning and performance (see, the related literature review); However, there have been very few studies, not to say almost no serious study, concerning the connection between music and language learning in Iran, especially the effect of a piece of classical music (Mozart Sonata) on the reading comprehension of Iranian English learners.

\section{Research Question}

So, this research question can be posed: Is there any significant difference between the result of reading performance of the Iranian English students taught reading comprehension passages in a music condition (Mozart Sonata condition) and that of those taught them in a non-music condition?

\section{Review of the Related Literature}

In a study by Rauscher, Shaw and Ky (1993) that showed the effect of music (Mozart Sonata) on the IQ of college students, the participants who had been exposed to Mozart Sonata for ten minutes scored higher on spatial-temporal reasoning tasks. It is interesting to see that Rauscher, Robinson and Jens (1998) conducted a similar study; this time not on humans but on rats, and achieved almost the same results. Rauscher (1988) reported that the Mozart work caused the rats to complete the maze faster and with fewer errors. She concluded that music effect can contribute to spatial learning of both rats and humans. It is also interesting to notice that an almost similar study conducted on plants; Retallack (1973) claimed that the plants exposed to soothing music grew abundantly and were extremely healthy.

"Compared with sitting in silence for $10 \mathrm{~min}$, listening to Mozart induces more positive moods and relatively optimal levels of arousal, which lead to higher levels of performance on tests of spatial abilities" (Schellenberg, 2004). However, Schellenberg (2004) claims that in subsequent studies replicating the Mozart Effect have been difficult.

In another study by Schellenberg (2004), two groups of students were given two different lessons, namely, music lessons and drama lessons. Before conducting the experiment, the researcher had measured the IQ of the two groups. Having conducted the study, Schellenberg (2004) concluded that in comparison with the drama group, the music group showed greater increases in full-scale IQ, so he asserts that "The effect was relatively small, but it generalized across IQ subtests, index scores, and a standardized measure of academic achievement."

Hallam, Price and Katsarou (2002) reported that in comparison with no-music condition, calming-music condition had better effect on the arithmetic and memory task performance of children, and in a study on the cognitive content drawing of children, Gur (2009) stated that classical music had a positive effect on this cognitive ability in children. More studies have been carried out which indicate the impact of music on general characteristics of the brain such as brain skills, memory, IQ, etc (see also, Rauscher \& Zupan, 2000; Stough, kerkin, Bates \& Mangan, 1994). Although the results of such studies may have different results at times, they show us that the inevitable effect of music on brain skills and activities cannot be simply underestimated.

Apart from the general effect of music on learners' IQ, brain functions and other cognitive abilities, in the literature of music and learning, specifically language learning, we can find a few studies concerning the different effects of music 
on the reading comprehension skill. Some of which are mentioned as follows:

Kelly (1981) explored the effect of music on the reading and language arts performance of first graders. The participants of the study were randomly divided into three groups, namely Orff-Schulwerk music, visual arts and control. Having analyzed both quantitative and qualitative data concerning the study, she stated that the effect of music contributed to the improvement of the music group to the level of the visual arts group and the control group, which had been at a higher level than the music group, with respect to reading and related areas. Kelly (1981) concluded that "Music shows a demonstrated potential for enhancing reading and language development in the first grade."

In another study by Cooper, Cotton and Goss (2008), the participants were given three different reading comprehension tests to do in three different conditions, namely no music, classical music, and lyrical music. The results showed a slightly better performance on the reading comprehension test in the no-music condition, but this difference was not significant $(\mathrm{p}=.94)$. Later on the researchers of the study recommended equalizing test difficulty before conducting a similar experiment.

In a similar study, Liapis, Giddens and Uhlenbrok (2008) tested the impacts of lyrical and non-lyrical music on reading comprehension. Participants were divided into two groups and each group was asked to read the same article under two different musical conditions, one while listening to a song with lyrics (lyrical condition) and the other while listening to the same song without any lyrics (non-lyrical condition). Participants in the non-lyrical condition had better scores; however, the difference was not significant $(\mathrm{p}=.552)$.

Drowns (2002) conducted a piece of research to see the effect of classical background music on silent reading comprehension. Although the results showed an improvement, the researcher doubted whether the improvement was due to the sole role of music or other factors were also involved. So, he suggested conducting more studies with this regard to shed light on other factors affecting reading comprehension as well.

Even a few studies were conducted that showed the positive effect of music on the reading skill of children who already had difficulties with their learning and were categorized as slow learners. Nicholson (1972 cited in Hodges \& O'Conell, 2005) reported that after having received music instruction, the slow learners got better reading scores than the learners who had not received any music instruction, and the results of Movsesian's study (1967 cited in Hodges, et al., 2005) were in line with those of Nicholson's (1972). In an almost similar study, Register, Darrow, Standley, and Swedberg (2007) reported that music made improvement in the reading skill of the students who had already had disability in reading. However, Lu (1986 cited in Hodges, et al., 2005) who had conducted a similar study did not find any significant differences between the group who had received music instruction and the other who had received no music instruction, and also the findings of Harmon, Troester, Pickwick and Pelosi (2008) showed that there was no significant difference among the three groups (rock group, Mozart group and silence group) on their reading comprehension test.

According to Harmon, et al., (2008) different studies have been conducted regarding the effects of different kinds of music on cognitive abilities and most of them have made use of the Mozart Effect (the benefit of listening to classical music over other sorts on learning), that is why the present study was also based on the effect of Mozart music on reading comprehension.

As it is evident, the results of the above reported studies have not been in line with each other at times. So, it implies that further research is needed to explore the effect of music on cognitive abilities including reading comprehension. Again it reminds us of the research question, that is: Is there any significant difference between the result of reading performance of the Iranian English students taught reading comprehension passages in a music condition (Mozart Sonata condition) and that of those taught them in a non-music condition?

\section{METHOD}

\section{A. Participants}

This study was conducted with two groups of male EFL learners at the age cohort of (17-21), with the same level of proficiency (already tested by ARCO TEOFL), studying at the Adult's High-intermediate 3 in the Iran Language Institute (ILI), Shiraz, Iran. Each group consists of 30 students. One group is treated as the control group, and the other as the experimental group. The non-probability sampling, accidental sampling, was utilized to select the participants.

\section{B. Instruments}

A passage with an interesting topic (i.e. The Race of Man) is chosen from MAN AND HIS WORLD by Patricia Milgrim. The passage includes 20 multiple-test items. Since the passage was published in a popular reading book for teaching reading comprehension passages, it was considered a standardized test, so its validity was taken for granted. The reliability of test was calculated by another group of the students of the same level of proficiency (also already tested by ARCO TEOFL) through applying KR-21 method. The result was the reliability of .82 so this test can be considered to be reliable. Another instrument was a DVD-player to broadcast the music (Mozart) at 50 decibel or dBA (a unit of sound pressure level).

\section{Data Collection and Procedure}

The participants of the present study belonged to two different classes: one class was treated as the control group and 
the other as the experimental group. They attended their classes 3 days a week for 24 sessions ( 2 months), and each session lasted for 105 minutes. These two groups had the same reading comprehension passages and teacher who was teaching them grammar, vocabulary and reading comprehension each session. The average time spent on each of these sections, namely grammar, vocabulary and reading comprehension was approximately 30, 35 and 40 minutes respectively. The reading comprehension was being taught within 40 minutes to the end of the class. The procedures for teaching reading comprehension were as follows:

1) Warming up on the passage: The teacher asks the students different questions concerning the subject of the passage to draw their attention to what they are going to read. (5 min.)

2) Silent reading: The teacher gives the students enough time to read the passage silently. (10 min.)

3) Asking general questions about the passage: The teacher asks the students general questions, concerning what they have read silently, to answer chorally, and subsequently repeats the general questions to have individual students give complete answers. (5 min.)

4) Paraphrasing the passage: The teacher reads out the passage sentence by sentence, and works on it by paraphrasing the paragraphs, asking detailed questions, and giving synonyms/ antonyms for certain words in the passage. (18 min.)

5) Assignment: The teacher wants the students to read the passage at home once more and make as many questions as they can on it. (2 min)

This five-stage procedure was followed exactly to teach reading comprehension passages to both the control and experimental groups. The only difference was that the experimental group was being exposed to music (Mozart Sonata) during teaching the reading comprehension passages.

On the 25th session the two groups (control and experimental) were given the same reading comprehension test, but in different conditions. The control group took the test in a condition where no music was being played; whereas, the experimental group took it in a condition where music (Mozart Sonata) was being played. The time allowed to take the test was 30 minutes for each group. After the administration of the tests, all the papers were collected and corrected by the researcher.

\section{Data Analysis}

An independent t-test was run to show if there had been any significant differences between the reading comprehension performance of the two groups (control and experimental) in different conditions (music and no music).

\section{RESULTS AND DISCUSSIONS}

The results of this study are shown in two tables, namely, table 1 and table 2 . First the study is analyzed with regard to descriptive statistics (table 1).

TABLE 1:

DESCRIPTIVE STATISTICS FOR THE TWO GROUPS OF NON-MUSIC/MUSIC ON THE READING COMPREHENSION TEST

\begin{tabular}{|l|l|l|l|l|}
\hline code & $\mathrm{N}$ & Mean & Std. Deviation & Std. Error Mean \\
\hline $\begin{array}{l}\text { The test mark in quiet } \\
\text { condition (non-music) }\end{array}$ & 30 & 16.8000 & 2.69866 & .49271 \\
$\begin{array}{l}\text { The test mark in music } \\
\text { condition (music) }\end{array}$ & 30 & 17.5000 & 1.35824 & .24798 \\
\hline
\end{tabular}

Regarding the mean scores of the two groups (music \& non-music), we see that the music group has a better performance on the reading comprehension test than the non-music group $(17.5>16.8)$. To see whether this difference between the mean scores was significant, a t-test was also run with the following results:

TABLE 2:

INDEPENDENT T-TEST FOR THE TWO GROUPS OF NON- MUSIC /MUSIC ON THE READING COMPREHENSION TEST

\begin{tabular}{|l|l|l|l|l|l|}
\hline $\begin{array}{l}\text { Mean difference between } \\
\text { non-music group } \\
\text { and music group }\end{array}$ & $\begin{array}{l}\text { Non music } \\
\text { group mean }\end{array}$ & $\begin{array}{l}\text { Music group } \\
\text { mean }\end{array}$ & df & t & Sig \\
\cline { 2 - 7 } & 16.8000 & 17.5000 & 42.608 & -5.602 & .03 \\
\hline
\end{tabular}

As evident in table 2, the difference between the means of the two groups is significant $(\mathrm{t}=-5.602, \mathrm{p}<.05)$.

Since the present study investigated the effect of music (Mozart Sonata) both on teaching reading comprehension and on testing it, the results were discussed in two respects: 1) The contribution of music to providing a suitable environment for enhancing language internalization in general. 2) The positive effect of music itself on reading comprehension performance in particular.

The experimental group of the study was taught reading comprehension passages in a music environment for two months, and then significantly outperformed the control group on the reading comprehension test. This improvement in the experimental group may have something to do with Krashen (1982) affective filter hypothesis in that when learners are in unfavorable situations they may develop an affective filter which in turn can reduce language internalization. So, it can be concluded that the music in this study, by reducing stress and negative emotions (Drowns 2002, Merrel 2004 and Stansell, 2005), may have created a favorable condition in which better reading comprehension learning took place.

Regarding the improving effect of music on the reading skill, the result of the present study showed consistency with 
Kelly's (1981) study in that music had a positive effect on the reading comprehension of the participants. Also, we saw this improving effect in the works of Nicholson (1972), and Movsesian (1967).

Cooper, et al., (2008) conducted almost a similar study with three different reading comprehension tests of different levels of difficulty; in the end they recommended that other researchers equalize test difficulty for further studies in the future. On their recommendation, in this study the researcher gave just one reading comprehension test from one source (MAN and HIS WORL) to both the control group and the experimental one, so that the test difficulty could not affect the results adversely. Besides, their research results (Cooper, et al., 2008) indicated a better performance on the reading comprehension tests in a no-music condition, and this difference was not significant $(\mathrm{p}=.94)$; however, in the present research the students' performance was better in the music condition, and it was significant $(\mathrm{p}<.05)$. Perhaps, one reason for different results in these two studies was the test difficulty as mentioned earlier (see the literature review).

\section{LIMITATIONS OF THE STUDY}

In doing this research, the researcher confronted few limitations: firstly, since the participants were all from Iran, the type of classical music (Mozart) exposed to them may not have been in line with their typically cultural music; however, Harmon, Troester, Pickwick and Pelosi (2008) state that " A variety of research has been conducted on the effects of different types of music on cognitive abilities. Many of these studies are based upon the Mozart effect. . ." So, the researcher wanted to base his study on research-based data that is why he made use of Mozart music. Secondly, the researcher was eager to have some female participants to evaluate the effect of this study on them. If he had access to female participants, he could also have run a two-way ANOVA to test the effect of gender on reading comprehension as well (the effect of two independent variables, music and gender, on reading comprehension could have been tested), but having access to female participants for a school or institute teacher in the context of the study was too difficult if not impossible.

\section{CONCLUSION}

Two groups of Iranian English students belonging to one English institute and also the same level of proficiency were taught and tested reading comprehension under two different conditions (music and no-music) within one term (2 months). The results of the study showed a significant difference between the reading comprehension scores of the two groups regarding the effect of music. Therefore, the answer to the research question was positive, that is, there is a significant difference between the result of reading performance of the Iranian English students taught reading comprehension passages in a music condition (Mozart Sonata condition) and that of those taught them in a non-music condition.

As the result of the study showed, English teachers can make use of music as an effective tool to facilitate students' language learning. Practically, applying music to all the teaching sections of a language class session may not be possible, but applying it to the reading comprehension section would be beneficial (as the results of the present study showed), and can bring variety to the language class as well.

\section{APENDIX 1: CLASSICAL MOZART MUSIC}

\section{APENDIX 2: DVD PLAYER}

\section{APENDIX 3: READING COMPREHENSION PASSAGE}

If you stood in a busy place in a big cosmopolitan city, like Times Square in New York City or Piccadilly Circus in London, and watched people go by, you would soon realize how intermixed the people of the modern world are.

Anthropologists speak of three major races of man. These races are identified as three distinct groups of people. Each group has certain physical characteristics that are inherited. These three groups belong to one family, and all may have been the same originally. However, as they moved to different parts of the earth, they developed different features adapted to the conditions of climate and food in the places where they lived for a long period of time. In more modern times, these groups of people have been intermixing. Some groups have been conquered; other groups have intermarried.

Nevertheless, if you watched the passers-by in Times Square carefully, you would probably recognize several major types of people. A man with yellowish skin, straight black hair, high cheekbones, and almond-shaped eyes probably belongs to the people of eastern Asia called the Mongoloid race. American Indians, who live in America and have reddish-yellowish skin, also belong to this group.

If a man is from Africa south of the Sahara Desert, he is likely to have a long head with black or dark brown skin; a broad, flat nose; thick, protruding lips; and tightly curled hair. He belongs to the Negroid race. Other men like him can be found in the South Pacific Islands.

A third group of men had their original home on the continent of Europe. This group is known as the Caucasoid race, because the earliest skull of this type of human being was found in the Caucasus Mountains region in southeastern Europe. The Caucasians are called the white race because their skin color is generally lighter than the yellow, brown, or 
black skin tones of the other races. People of the white race have a variety of head shapes, and their hair varies from silky straight to curly. People of this race living near the Mediterranean Sea are usually darker-haired and darker-eyed than people in areas farther north. Nowadays people of the Caucasoid race live in all parts of the world.

Some scientists speak of a fourth group, the Australoids, who are dark-skinned aborigines living on the continent of Australia. There are also some people, like the Ainu of Japan, who do not seem to belong to any one of the major races.

If you wanted to make a map showing the races of mankind, it could not have only three or four colors for the main racial groups; it would have to show many tints and shades. As men mingle more and more in the modern world of easy travel, the races become more intermixed. It is sometimes difficult to label a man as belonging to one race or another. Is it even desirable to emphasize the differences between races? Man's great problem is to learn how to live peacefully with people different from himself. As members of one family, men must "live like brothers or die like beasts."

\section{APPENDIX 4: TEST}

Choose the right answer.

1) The writer of the passage is probably...

A . standing in the middle of a large city.

B . living in New York City or London.

C . trying to make the reader think about a situation.

D . watching people walk along busy streets.

2) "... how intermixed the people of the modern world are. "means...

A. How are the people of the modern world mixed together?

B . The many different people of the world have become mixed to a great degree.

C. The people of the modern world are very mixed up.

D. How did the people of the modern world become mixed?

3) In paragraph 2, line 1, "major" has the same meaning as...

A. He's a chemistry major.

B . His brother is a major in the army.

C. They are majoring in engineering.

D . A major problem in Tehran is the traffic.

4) In paragraph 2, all of the following are stated except:

A . All men might have been the same in the beginning.

B . Man's features changed because of the climate in which he lived.

C . Today the original three groups of men are more distinct than they used to be.

D . Conquest and intermarriage have caused the races of man to become mixed.

5) There are two words with INTER-, intermarry and intermix. The prefix INTER- means...
A . between
B . from
C. from
D. to

6) In paragraph 2, line 4, "However" means...
A . and then
B . and since
C. but when
D . in that way

7) All of the following statements about the people of the Mongoloid race are true except:

A. They all live in eastern Asia.

B . Their skin is yellow or reddish-yellow.

C . Their hair is straight and black.

D . They include the American Indians.

8) In paragraph 4, line 1, "likely" means...

A. he has

B . he wants to have

C. he likes to have

D . he probably has 
9) In paragraph 4, line 3, like has the same meaning as...

A. Jack doesn't like New York City.

B . It is likely to rain tomorrow.

C . He's a likable boy.

D . Mary is just like her sister.

10) All of the following statements about the people of the Negroid race are true except:

A. Their hair is curly.

B . They have protruding cheeks.

C. Their skin is dark.

D. They are found in Africa and the South Pacific Islands.

11) All of the following statements about the members of the Caucasoid race are true except:

A . Although they originated in Europe, they are found in all regions of the world today.

$\mathrm{B}$. The name of this race is connected with a geographical site.

C. They all have light skin and hair.

D . Some of its members live near the Mediterranean Sea.

12) In paragraph 5 , line 4 , "lighter" has the same meaning as...

A. Turn on the light.

B . Please light my cigarette.

C . You can easily carry that box because it's light.

D. That shirt is light blue.

13) "... their hair varies from silky straight to curly." means...

A. Their hair is silky straight, wavy, or curly.

B . They have either silky straight or curly hair.

C . Their hair is different from silky straight and curly.

D . Their hair changes from silky straight to curly.

14) Which of the following statement is true?

A. The Australoids have dark skin and live in Austria.

B . The Ainu and the Australoids belong to the same race.

C. The Ainu live in Japan.

D . Scientists know nothing about the Australoids.

15) An accurate map of racial groups would have...

A. only three or four colors.

B . many light and dark shades of color.

C . only two main racial groups on it.

D . many racial groups unknown to anthropologists.

16) In paragraph 7 , line 2, "it" refers to...

A. a race

B . a color

C . a main racial group

D . a map

17) " As men mingle more and more in the modern world of easy travel,... " means...

A . Easy travel in the modern world makes more mingling of men possible.

B . Men in the modern world want to travel and mingle more easily.

C . If more men mingle, more men will travel.

D . More and more men travel easily because they mingle in the modern world.

18) From the context, paragraph 7 ,line 4 , label means...

A. find

B . identify

C . vary

D . adapt 
19) "Man's great problem is to learn how to live peacefully with people different from himself." The underlined part of this sentence means...

A . how does man live peacefully with people different from himself?

B . how man lives differently from peaceful people.

C . how people different from himself live peacefully.

D . how man can live peacefully with people different from himself.

20) In the last paragraph, what does the last sentence mean?

A . The brothers of men die like beasts.

B . If man's brothers live in peace, beasts will not die.

C . If men do not accept other men, they are like animals.

D . Men live liking their brothers and die liking beasts.

\section{REFERENCES}

[1] Chastain, K. (1988). Developing second language skills: Theory and practice (3rd ed.). New York: Harcourt Brace Jovanovich Publishers.

[2] Cooper, A., Cotton M., \& Goss, S. (2008). The effect of music on reading comprehension. Hanover College. Retrieved August 19, 2010 from http://vault.hanover.edu/ altermattw/methods/assets/posterpics/Fall2008/Cooper_Cotton_and_Goss.pdf

[3] Drowns, M. R. (2002). The effect of classical background music on fourth-grade silent reading comprehension. Unpublished M.A. Thesis, Truman State University, Division of Education, Kirksville, Missouri. Retrieved August19,2010 from http://www2.truman.edu/ ed27/eg_folio/mdrowns/evidence_reflection/1.2.9/internship_notes.pdf

[4] Gur, C. (2009). Is there any positive effect of classical music on cognitive content of six year-old children in Turkey? European Journal of Scientific Research, 36 (2), 251-259. Retrieved August 24, 2010 from http://www.eurojournals.com/ejsr_36_2_08.pdf

[5] Hallam, Price \& Katsarou. (2002). The effects of background music on primary school pupils' task performance. Educational Studies, 28 (2), 111-122. Retrieved August 24, 2010 from http://coe.georgiasouthern.edu/foundations/bwgriffin/edur7130/RR_backgroundmusic.pdf

[6] Harmon, L., Pelosi, G., Pickwick, T., Troester, K. (2008). The effects of different types of music on cognitive abilities. Journal of Undergraduate Psychological Research, 3, 41-46. Retrieved August 20, 2010 from http://library.wcsu.edu/dspace/bitstream/0/456/1/harmon.pdf

[7] Hodges, D. A., \& O'Connell, D. S. (2005). The impact of music education on academic achievement. The University of North Carolina at Greensboro. Retrieved August 20, 2010 from http://www.uncg.edu/mus/SoundsOfLearning/AcdemicAchievement.pdf

[8] Jalongo, M. \& Bromley, K. (1984). Developing linguistic competence through song. Reading Teacher, 37 (9), 840-845.

[9] Jolly, Y. (1975). The use of songs in teaching foreign languages. Modern Language Journal, 59 (1), 11-14.

[10] Kelly, L. L. (1981). A combined experimental and descriptive study of the effect of music on reading and language. Unpublished Ph. D. dissertation, University of Pennsylvania. Retrieved August 23,2010 from http://repository.upenn.edu/dissertations/AAI8117801/

[11] Krashen, S. (1982). Principles \& practice in second language acquisition. Oxford: Pergamon Press. Retrieved August 19, 2010 from http://www.sdkrashen.com/Principles_and_Practice/Principles_and_Practice.pdf

[12] Larsen-Freeman, D. (2000). Techniques and principles in language teaching (2nd ed.). Oxford: Oxford University Press.

[13] Liapis, Z., Giddens, Z. \& Uhlenbrock, M. (2008). Effects of lyrical music on reading comprehension. Retrieved August 20, 2010 from, http://vault.hanover.edu/ altermattw/methods/assets/posterpics/Fall2008/Giddens_Liapis_and_Uhlenbrock.pdf

[14] Martin, M. (1983). Teaching spelling with music. Academic Therapy, 18 (4), 505-515.

[15] McCarthy, W. (1985). Promoting language development through music. Academic Therapy, 21 (2), 237-242.

[16] Merrell, A. (2004). The benefit of incorporating music in the classroom. Retrieved August 19, 2010 from http://Audreymerrell.net/INTASC/INTASC6/the\%20benefits\%20of\%20incorporating\%20music.pdf

[17] Rauscher, F. H., Robinson, K. D., \& Jens, J. (1998). Improved maze learning through early music exposure in rats. Neurological Rresearch, 20, 427-432. Retrieved August 21, 2010 from http://www.uwosh.edu/psychology/rauscher/NeuroResRat.pdf

[18] Rauscher, F. H., Shaw, G. L., \& Ky, K. N. (1993). Music and spatial task performance. Nature, 365, 611. Retrieved August 21, 2010 from http://www.uwosh.edu/psychology/rauscher/Nature93.pdf

[19] Rauscher, F. H., \& Zupan, M.(2000). Classroom keyboard instruction improves kindergarten children's spatial-temporal performance: A field experiment. Early Childhood Research Quarterly, 15, 215-228. Retrieved $\quad$ August 21, 2010 from http://www.uwosh.edu/psychology/rauscher/ECRQ.pdf

[20] Register, D., Darrow A. A., Standly, J. \& Swedberg, O. (2007). The use of music to enhance reading skills of second grade students with reading disabilities. Spring, 44 (1), 23-37. Retrieved September 3, 2010 from http://www.ncbi.nlm.nih.gov/pubmed/17419662

[21] Retallack, D., L. (1973). The sound of music and plants. Retrieved August 21, 2010 from http://www.dovesong.com/positive_music/plant_experiments.asp

[22] Richards, J. C., \& Rodgers, T. S. (2001). Approaches and methods in language teaching (2nd ed.). Cambridge: Cambridge University Press.

[23] Schellenberg, G. (2004). Music lessons enhance IQ. American Psychological Society, 15 (8), 511-514. Retrieved August 19, 2010 from http://www.psychologicalscience.org/pdf/ps/musiciq.pdf

[24] Stansell, J. W. (2005). The Use of Music for Learning Languages. University of Illinois at Urbana-Champaign. Retrieved 
August 20, 2010 from

http://mste.illinois.edu/courses/ci407su02/students/stansell/Jon_Stansell_The_Use_of_Music_in_Learning_Languages.pdf

[25] Stough, C., Kerkin, B., Bates, T., Mangan, G. (1994). Music and spatial IQ. Personality Individual Differences, 17 (5), 695.

Nasser Rashidi has got his BA in Teaching English as a Foreign Language (TEFL) from Shiraz University in 1991. He has got his MA in TEFL from the same university in 1995. He received his PhD in TEFL from Shiraz University in 2002. He is presently the academic member of the Department of Foreign Languages and Linguistics at Shiraz University. His area of research is TEFL including language teaching and testing, discourse analysis and sociolinguistics. He has written two books and about 19 articles on topics in the areas mentioned.

Farman Faham is an MA student of TEFL at Shiraz University. His area of interest is Language teaching. 